\title{
The polluter should... pay?
}

\author{
Funda Yetgin Baykal ${ }^{1 *}$ \\ ${ }^{1}$ Ministry of Environment and Urbanization (MoEU) ${ }^{1}$, Turkey
}

*Corresponding author: funda.yetgin@csb.gov.tr

The Author(s)
Published by ARDA.
The Polluter Pays Principle (PPP) is among the core international instruments for
environmental protection. It appears to be excessively economy-focused at initial
sight. To evaluate the moral validity of this, I visited four different justification
possibilities: 1. Economically preferable equals environmentally preferable; 2 .
Economic development is a satisfactory aim; 3 . Environmental problems arise
from economic goals; 4 . The economy represents the power needed for solutions.
After evaluating each of these, I confirmed that the focus of the PPP on the
economy does not allow for sufficient protection of Nature, as also expressed in
the literature.

Keywords: Polluter Pays Principle, Nature, Market, Economy, Environmental ethics

\section{Introduction}

This study aims at analyzing and discussing the "Polluter Pays Principle" (PPP). The OECD is reported to be the first to explicitly mention the PPP in 1972 [1]. In its Recommendation ([2], Annex A.a.4), it was written that the PPP is there "to encourage rational use of scarce environmental resources and to avoid distortions in international trade and investment", that it covers the expenses for the measures "to ensure that the environment is in an acceptable state". The PPP was also adopted as Principle 16 of the United Nation's Rio Declaration [3], which mentions that "the polluter should, in principle, bear the cost of pollution", again "without distorting international trade and investment." The Environmental Liability Directive (ELD) is the EU's major legal tool based on the PPP, which mentions ([4], Article 1.3.3 of Annex II) that complete remediation is not compulsory if the environmental benefit is not worth the economic costs. Moreover; the ELD reveals that protected species and natural habitats, water and lands are considered as "natural resources". Article 2.16 of ELD cites the following cost items within the PPP: "the costs of assessing environmental damage, an imminent threat of such damage, alternatives for action as well as the administrative, legal, and enforcement costs, the costs of data collection and other general costs, monitoring and supervision costs". An expected function of the PPP's payments is deterrence or induction. The main principle of ELD is mentioned as: "that an operator whose activity has caused the environmental damage or the imminent threat of such damage is to be held financially liable, in order to induce operators to adopt measures and develop practices to minimize the risks of environmental damage so that their exposure to financial liabilities is reduced." On the other hand, Hulme and Short [5] and Tekayak [6] argue that PPP fines are not deterrent for companies. They defend that financial means are not satisfactory for environmental protection and propose a strict international law which would regard environmental damages as criminal activity instead. The expressions about the PPP

1 Disclaimer: The views and opinions expressed in this article are those of the author and do not necessarily reflect the official policy or position of the Ministry.

This work is licensed under a Creative Commons Attribution License (https://creativecommons.org/licenses/by/4.0/ ) that allows (C) (i) others to share and adapt the material for any purpose (even commercially), in any medium with an acknowledgement of the work's authorship and initial publication in this journal. 
given in the first paragraph seem to be excessively economy-oriented. This is problematic because if the focus point is economy, it means that it is not exactly the Nature. The goal hence may seem like protecting or aligning with the economic framework and the free market, which does not sound prima facie to be exactly good or sufficient for the Nature.

The economy-focus (or, excessive focus on or overemphasis of economy) is not confined to the word "Pays". Naming some parts of the Nature as "natural resources" implies that these parts, which also include living beings, can be used and traded based on market values. Meanwhile Redford and Adams [7] have a remark about ignorance of the non-market-based value of Nature in market policies. Moreover, even the decision regarding whether to conduct remediation is allowed to be made based on whether or not it is economically costly. This alone could be enough for demonstrating the preference of the economy over the environmental protection. Whenever made, the extent of the remediation to be made is subjective, as revealed by the term "acceptable state". The defined extent of remediation is also proportional to the scope of the "defined" damage [8]. Zhu and Zhao also mention (ibid) that, the harms of environmental damage are not confined to the reasonable costs of remediation, which is relevant to what acceptable state is. The anthropocentric and non-anthropocentric approaches in the environmental ethics literature bring further different perspectives to these aspects. Based on all these, in this study, I would like to explore in the Discussion if the economy-focus of the PPP could indeed be justified. The possibilities I will evaluate for the justification are listed below:

1) Economically preferable $=$ Environmentally preferable

2) Economic development is a satisfactory aim

3) Environmental problems arise from economic goals

4) Economy represents the power needed for solutions

\section{Discussion}

I will visit every possible justification in different sections in the order above.

\subsection{Economically preferable $=$ Environmentally preferable}

Here we may initially think of two sub-possibilities (I will present a possible amendment in the coming paragraphs):

i) the scope of Nature to be protected $=\sum$ (natural resource of economic worth)j

ii) Even if not i), it is for the benefit of Nature to treat it as such (protecting the natural resources leads to protection of the Nature)

The equality in the first sub-possibility would hold true if those termed as environmental resources were truly merely resources and furthermore, if environment consisted of nothing more than those so-called resources. This is against many non-anthropocentric views and I will start with these. They are not omittable, because at least some of the living beings have sentience or are subject-of-a-life, which make them morally considerable, with respect to the different criteria of Peter Singer's animal welfare or Tom Regan's animal rights approaches respectively. We can also say not omittable because all living beings have intrinsic value (defended by e.g. Kenneth Goodpaster [9]). There are some beings which have a right or at least need to -but cannot- object economy-focused interactions with the Nature. Deep ecology also regards exclusion of some noneconomically valuable entities as totally unacceptable. This list of criteria and approaches can be extended ${ }^{2}$, but the point is that the non-anthropocentric views would reject this possibility of justification. They would also reject the second sub-possibility. Because these beings worthy of consideration outside the focus would be ignored (thus could be harmed) whilst "natural resource" focused endeavors. The Nature is an integration of many subsystems, species (and their individual members and colonies etc.), as well as non-living parts.

\footnotetext{
${ }^{2}$ There are possible additional criteria. But selection of criteria is a deep issue and it suffices for the purposes of this paper to mention that non-anthropocentric views would oppose the omission, protesting against the look at humankind as holder of the right to freely utilize the rest of beings as resources.
} 
Acting with the natural resource perspective may not protect the parts of the Nature that are generally not required to be protected for the sake of economics, such as areas with low-economic-value "natural resources" or economically-dispensable areas or non-humans ${ }^{3}$ These are however parts that are of concern for nonanthropocentric views.

Anthropocentric views focus on the value of and aim the good for the humans, not attributing much worth to the non-humans and the Nature. The first sub-possibility may thus prima facie fit those views. Keeping in mind that the Nature has many parts additional to those with economic worth, let us analyze if this view really serves humans. I argue that this view is in reality self-damaging for the human population. Because the humanity is not at the top of the possible level of knowledge (e.g. please consider the knowledge deficits about ocean life [10]) or the general knowledge deficits about the ecosystems arising from insufficiency of Newtonian framework ([11], p. 9). We would not be able to tell with utmost accuracy which resources should be used carefully or freely or instead totally preserved, and which factors they depend on in the complex web of nature. When it comes to interdependencies in this web, we do not have a strong enough habit of thinking integrally about the Nature either (some of the problems regarding anticipation or implementation of Industrial Emissions Directive or regulatory impact assessments could be given as examples). E.g. it is possible to act without real knowledge on the value of a plant species that could be pharmaceutically useful ${ }^{4}$ or which factors its wellbeing depends on. We may discard this "ignorable" plant species while protecting the "collection of natural resources" there. If we do not have these necessary knowledge or habits at a sufficient level, an ignorant look to the Nature as a set of resources would actually mean an ignorant look to the future of the humanity ${ }^{5}$. Thus "rational use of natural resources" may not be a very realistic perspective. The objection above also holds true for the second sub-possibility in the anthropocentric domain, for similar reasons. This sub-possibility could be formulated in this domain as taking care of the essential parts of the Nature for the sake of humans, by sustainably taking care of the natural resources against depletion or deterioration. The same objection is valid, the Nature being an integration of many subparts and the humankind lacking some skills and knowledge to sufficiently address this whole matrix.

We may amend the two sub-possibilities by including some additional parts that are necessary for protection of the parts of economic worth. For example, the parts that connect and/or support and/or are inseparable from the parts of economic worth can thus be included within the considerations. This amendment however may still not cover all the non-anthropocentrically-valuable parts of the Nature, e.g. some sentient non-humans or the parts that do not demonstrate clear ecological significance. Thus the non-anthropocentric view would still object the first justification possibility (the two sub-possibilities). When we consider the anthropocentric views, we reach the same conclusion of objection. This is due to lack of knowledge and skills to target the parts that are necessary for the parts of economic worth.

Still a better approach could be to make the amendment in a very broad sense, so that the context includes all the parts and beings that should not be left aside. Perhaps, it is better to focus on the whole matrix. This means the whole web of Nature, the whole ecosystem. Meanwhile finally this is a point where the justification possibility satisfies both anthropocentric and non-anthropocentric approaches. But then the justification possibility loses its point: Why should we regard the Nature with a focus on the economically valuable parts, if we are finally to take into account the whole Nature?

Actually it is not a surprise that this first justification possibility fails. As also mentioned by Zhu and Zhao [8], harmful impacts of environmental damage cannot be assumed to be identical to economic harm. While it is true that many aspects have economic outcomes, this does not mean that everything can or should be viewed

\footnotetext{
${ }^{3}$ This claim is also used for poor humans and future humans in various studies in the literature.

${ }^{4}$ This instrumental example is given to represent the anthropocentric perspective mentioned.

${ }^{5}$ While the environmental protection field also includes the Precautionary Principle for new array of activities posing uncertainties, still, whether or not we know enough about how much we know and how much we lack information in which fields is also questionable.
} 
in economic terms. An issue may be really insignificant as a whole in terms of economics, despite not being so in terms of environment. Furthermore; some economic results of the environmental changes cannot be accurately quantified. This gap of information can lead to omission or exaggeration of the real economic result. In a world where the economic area receives an excessive attention and because that the Nature as a whole (and its many parts) are not integral parts of economic calculations, probably the effects of these is generally in the direction of omission of real value rather than exaggeration. Note that this possibility for justification about limitation of the scope of the Nature to protect is also relevant to the discussion below within the context of the possible justification 3, as the limitation is linked to "preferences" and "priorities" that may obviously bring barriers to environmental protection.

\subsection{Economic development is a satisfactory aim}

The economy-focus could be regarded as an aim (end) in the form of economic development. Aim possesses significance, and is more than a tool ("mean"). This possibility may provide answers to many criticisms. But when viewed together with some other aims such as happiness, wellbeing, freedom, strength or so on, the economic development does not necessarily shine out as the ultimate aim. Economic development should perhaps be regarded as a tool for such other (higher level) aims. Probably it is one tool that is successful to some extent for attaining such higher aims. There is no single reason to think that a good economic status is still worthy even when it does not facilitate attaining such a higher aim. Human development can be considered as an intermediate level aim in the objective tree (aim with respect to the aims below, tool with respect to those higher level aims). Human development is definitely important but economic development is not the only means to reach it and the latter does not guarantee the first. Failure could be due to several factors, one being simply the mentioned fact that human development is more than economic development of the humans, being measurable by life expectancy and literacy [12]. Here, life expectancy of humans is associated with not just the economic development status of the humans but also many other factors including, inter alia, the status of the environment they directly or indirectly interact with. While environmental status deterioration could be partly prevented with a sustainable economic development approach, still no reason could be found to focus more on the economy than the Nature.

Another factor to consider is whether or not an additional aim of "development" of the humankind (in a broader sense than the above "human development") can be considered as a valid higher aim by itself too, rather than merely a tool for higher aims. It is the state of progress of the humankind. Meanwhile, the development is not always in positive direction: would or would not the World be better without inventions of atom bomb or biological weapons? On the other hand, if "development" is still to be taken as a higher aim, it is much wider a concept than economic development. If economic development fits into it, so can environment-friendliness development of the humankind fit into it. Based on all above, overemphasis on economic development is still not justified.

\subsection{Environmental problems arise from economic goals}

The economy-focus may be based on the grounds that crimes committed by companies are generally committed with aims of financial profit and by the effect of the competitive nature of the market. Here the idea is that the PPP can "induce operators to (...) minimize the risks of environmental damage" as mentioned in ELD and transform the highly competitive market where companies are after economic gains to a market where companies also consider protection of the environment. I would like to call the PPP in this context as a potential "shaping" tool ${ }^{6}$ to shape the market. If wrong action is not economically punished, due to the

\footnotetext{
${ }^{6}$ While my understanding is that within the framework of the PPP the market could in theory be shaped as an environment-friendly market by both sanctions and consumers, I will not go into detail about the role of the consumers in this short paper. Let me only mention that the major handicaps mentioned in the paper against the success of the PPP in shaping the market (e.g. highly competitive conditions, strength of freely acting companies relative to the fines) are also barriers for the role the consumers can perform to shape
} 
economic revenues gained by the wrongdoers, there will be an economic inequality between these companies and the innocent companies, to the benefit of the first. In this way, no economic punishment to the damager companies seems to be an economic punishment to the companies which do not damage. This inequality can adversely shape the market as a non-environment friendly market, by not just weakening the environmentally innocent companies, but also leading them to commit the same crimes, because it would seem possible to them to escape from justice like those free riders. Thus, effective punishment of the environmental harms is relevant to justice as well as effectiveness (providing deterrence). But there are problems. The problems are such that, the shaping tool can shape the market towards one with lower environmental priorities and more ambitious pursuit of self-interests. Below I will discuss this and additionally the option of elevation of fines.

Regarding lowered environmental priorities, it should first be reminded that even without the PPP, when companies have to be in a continuous and possibly harsh race with each other, their attention to moral concerns (justice or others) and sensitivities (towards other humans, the Nature or its components) may decrease. They may proceed to a consequentialist summation to decide on whether or not a considered environmental damage would be worth the harms of it, simply focusing narrowly on only the harms and benefits to themselves. These companies could otherwise perish. In that case, through increased and rather free consideration of the possible consequences for the self, the acts obviously would not be determined by environmental sensitivities ${ }^{7}$. These companies may choose to give more environmental damage. Because anything with a price tag is not completely prevented: there is a choice of violation depending on economic strength and priorities. As a result of this freedom, the market would be ironically shaped as a market with weakened environmental priorities for the Nature or its parts.

Meanwhile, under effect of the abovementioned continuous harsh competition, the market may be undergoing another shaping procedure, eliminating the weaker ones. Since the same amount of sanction have different levels of effects on environmental damagers of different economic strengths, justice questions come to mind. But I do not believe that every company has to exist or maintain the same financial strength forever. The companies facing difficulty should indeed be able to shoulder their own responsibilities with respect to the Nature, as a minimum. In this respect; the capability (financial and else) relative to the risk of the task has importance: Because that the financially insufficient companies may not have the power to account for their environmental damage, it does not have to be morally wrong by itself that they face difficulties and even closure and insolvency, when attention is paid to not these companies alone but also all potential victims of possible environmental damage.

A negative environmental consequence of insolvency however is that some companies fail to afford the recovery of the damage they had caused (e.g. [13] mentions this problem about the duty of compensation towards the human victims). Some authors propose guarantee mechanisms to prevent this situation (e.g. [8] propose pre-collected funds). The EU ([14], Article 16) similarly proposes financial security instruments, meanwhile stating a belief that the demand is low yet. If feasible, such measures could be a solution.

As another important aspect, does it morally suffice to cover only the remediation ${ }^{8}$ to account for the damage? I believe not, because remediation does not undo some harms of the environmental damage such as lost or harmed lives. Then, whenever the PPP fines should be given, they should involve additional amounts to account for the irremediable harms given. The decision on additional amounts however brings the difficulty of how the value of lives would be estimated, when there is such a wide spectrum of non-anthropocentric approaches. One way is to overcome this difficulty by setting the PPP fines at astronomic amounts. But even an astronomic amount is still an amount to pay. Thus, the price-tag freedom again holds true for some (this

the market as an environment-friendly one (accompanied with other barriers such as information and awareness gap, social constructs and alike) within the framework of the PPP.

${ }^{7}$ Such as those deriving from animal rights, ecological or deep ecological, virtue-oriented approaches or, as another but still nonanthropocentric form of consequentialism, from animal welfarism.

${ }^{8}$ We can consider the costs mentioned in abovementioned Article 2.16 of ELD within this context. 
time "very") strong companies. It is still not a state of total justice or a totally effective measure if the strongest can breach. The most appropriate alternative to the PPP from this point of view appears to be nonfinancial measures (e.g. criminal law, praising and shaming).

All in all, although environmental problems frequently arise from economic pursuits, an economy-focused instrument is not enough ${ }^{9}$, can bring inequalities and fails as a shaping tool due to what I explained as pricetag freedom. While elevation of fines seems necessary, it is not an exact solution either.

\subsection{Economy represents the power needed for solutions}

The market, the platform of money exchanges, can represent the energy flow and has many influences. The money can represent the energy (or let's say the power, forgetting about the technical difference of these two terms for our purposes). These can affect, influence, and perhaps even control many things. Thus, if an instrument is in harmony with free market or allows utilization of money for environmental protection, this seems beneficial. But seeking harmony as a means for success may sometimes be against the aim for which we would like to succeed with the means. If a moral aim is of concern, this would resemble the situation of submitting to the power and forgetting about morality. To check, we can observe progress towards the aim for example, in addition to possible moral problems.

In European Parliament's resolution on the ELD ([14], particularly through Articles 9-11), it is mentioned that significance of environmental damage is defined differently across EU Member States and regrettably by excluding concerns about the Nature, and that ELD is not applied to some important environmental damages. Thus the ELD (the widest legal instrument of the PPP) does not sufficiently serve environmental protection goals and fails to address the Nature sufficiently. Thus; in addition to the moral problems mentioned in the preceding parts, the excessive reliance on economy for power is not justified on grounds of success either.

\section{Conclusion}

The PPP is a global environmental protection instrument. It is clearly an instrument with economy-focus -not limited to "Pay" in its name, but also involving the economy-focus much in other additional ways. The intensity of this focus makes the PPP's fit into the environmental protection picture questionable. In this short paper, I visited four different possibilities for justification of the economy-focus. It was seen in the preceding parts that these justification possibilities do not work. The idea that the polluter should "pay" for the environmental damage and that economic expenditure is the mechanism for the punishment and deterrence does not suffice for environmental protection. It does not allow sufficient address of the Nature. It is not good for us humans either. But it allows the potential damagers to utilize a price tag freedom and involves moral problems. To conclude, I agree with the claims that financial punishments do not constitute the best option. Yet they should be implemented fairly and with goals of protecting Nature whenever they are implemented. As long as the current system is valid, the following should be addressed: establishment of a paymentguarantee system, elevation of fines to account for all damages including those to the lives in the Nature.

Recommendation topics for further studies involve the following:

- Could a strict international law really be an alternative? For this, how will countries unite to enact such a law that may also bring them disadvantages?

- Could praising and shaming be an alternative? For this, how should the following problems be overcome?: Lack of awareness, non-standardized environmental claims of companies, abundance of breachers and free riders who elevate the psychological and social limit for shame.

\footnotetext{
${ }^{9}$ In fact another objection is that economics oriented environmental solutions exclude other necessities (an example could be lifestyle change), as mentioned by York and Rosa [15]. There are additionally numerous studies on whether or not and how important a role individual have, as consumers and citizens. As mentioned before, I will not elaborate on consumers in this short paper.
} 


\section{Acknowledgement}

This paper is based on part of an MA thesis study conducted in 2015-2016 in LiU (Sweden) with the EU's Jean Monnet Scholarship Programme (coordinated in Turkey by the Ministry of Foreign Affairs - Directorate for EU Affairs). The thesis for this MA Applied Ethics was titled "Moral Evaluation of the PPP" and supervised by Prof. Dr. Anders Nordgren.

\section{References}

[1] P. Sands, J. Peel, A. F. Aguilar, and R. MacKenzie, Principles of International Environmental Law. Cambridge: Cambridge University Press, 2012. doi: 10.1017/CBO9781139019842.

[2] OECD, "Recommendation of the Council on OECD Legal Instruments Guiding Principles concerning International Economic Aspects of Environmental Policies, OECD/LEGAL/0102," May 1972. [Online]. Available: http://legalinstruments.oecd.org

[3] UNDP, "Rio Declaration on Environment and Development," 1992. [Online]. Available: http://www.un.org/documents/ga/conf151/aconf15126-1annex1.htm

[4] European Parliament and the Council of the European Union, "Directive 2004/35/CE of the European Parliament and of the Council of 21 April 2004 on Environmental Liability with Regard to the Prevention and Remedying of Environmental Damage - consolidated version," 2013.

[5] K. Hulme and D. Short, "Ecocide and the Polluter Pays Principle: The Case of Fracking," 2014.

[6] D. Tekayak, "Critical Review: From 'Polluter Pays' to 'Polluter Does Not Pollute," Geoforum, vol. 71, pp. 62-65, 2016.

[7] K. H. Redford and W. M. Adams, "Payment for ecosystem services and the challenge of saving nature: Editorial," Conservation Biology, vol. 23, no. 4. pp. 785-787, Aug. 2009. doi: 10.1111/j.15231739.2009.01271.x.

[8] L. Zhu and Y. C. Zhao, "A feasibility assessment of the application of the Polluter-Pays Principle to ship-source pollution in Hong Kong," Marine Policy, vol. 57, pp. 36-44, 2015, doi: https://doi.org/10.1016/j.marpol.2015.03.010.

[9] K. E. Goodpaster, "On Being Morally Considerable," The Journal of Philosophy, vol. 75, no. 6, Jun. 1978, doi: 10.2307/2025709.

[10] W. Appeltans et al., "The magnitude of global marine species diversity," Current Biology, vol. 22, no. 23, pp. 2189-2202, Dec. 2012, doi: 10.1016/j.cub.2012.09.036.

[11] P. Miller and W. E. Rees, "Introduction," in Ecological Integrity: Integrating Environment, Conservation and Health, no. 1, D. Pimentel, L. Westra, and R. F. Noss, Eds. Island Press, 2013, p. 108. doi: 10.1016/s0167-8809(02)00023-3.

[12] P. Streeten, "Human Development: Means and Ends," American Economic Review, vol. 84, no. 2, pp. 232-237, 1994, [Online]. Available: https://EconPapers.repec.org/RePEc:aea:aecrev:v:84:y:1994:i:2:p:232-37

[13] B. Luppi, F. Parisi, and S. Rajagopalan, "The rise and fall of the polluter-pays principle in developing countries," International Review of Law and Economics, vol. 32, no. 1, pp. 135-144, Mar. 2012, doi: 10.1016/j.irle.2011.10.002.

[14] European Parliament, "European Parliament Resolution of 26 October 2017 on the application of Directive 2004/35/EC of the European Parliament and of the Council of 21 April 2004 on environmental liability with regard to the prevention and remedying of environmental damage (the 'ELD') (2016/2251(INI)),' 2017.

[15] R. York and E. Rosa, "Key Challenges to Ecological Modernization Theory: Institutional Efficacy, Case Study Evidence, Units of Analysis, and the Pace of EcoEfficiency," Organization \& Environment - ORGAN ENVIRON, vol. 16, pp. 273-288, Sep. 2003, doi: 10.1177/1086026603256299. 